Article

\title{
Applying Different Configurations for the Thermal Management of a Lithium Titanate Oxide Battery Pack
}

\author{
Seyed Saeed Madani *(D), Erik Schaltz (D) and Søren Knudsen Kær (D) \\ Department of Energy Technology, Aalborg University, DK-9220 Aalborg, Denmark; esc@et.aau.dk (E.S.); \\ Skk@et.aau.dk (S.K.K.) \\ * Correspondence: ssm@et.aau.dk
}

check for

updates

Citation: Madani, S.S.; Schaltz, E.; Kær, S.K. Applying Different Configurations for the Thermal Management of a Lithium Titanate Oxide Battery Pack. Electrochem 2021, 2, 50-63. https://doi.org/10.3390/ electrochem 2010005

Received: 4 January 2021

Accepted: 21 January 2021

Published: 23 January 202

Publisher's Note: MDPI stays neutral with regard to jurisdictional claims in published maps and institutional affiliations.

Copyright: (c) 2021 by the authors. Licensee MDPI, Basel, Switzerland. This article is an open access article distributed under the terms and conditions of the Creative Commons Attribution (CC BY) license (https:/ / creativecommons.org/licenses/by/ $4.0 /)$.

\begin{abstract}
This investigation's primary purpose was to illustrate the cooling mechanism within a lithium titanate oxide lithium-ion battery pack through the experimental measurement of heat generation inside lithium titanate oxide batteries. Dielectric water/glycol (50/50), air and dielectric mineral oil were selected for the lithium titanate oxide battery pack's cooling purpose. Different flow configurations were considered to study their thermal effects. Within the lithium-ion battery cells in the lithium titanate oxide battery pack, a time-dependent amount of heat generation, which operated as a volumetric heat source, was employed. It was assumed that the lithium-ion batteries within the battery pack had identical initial temperature conditions in all of the simulations. The lithium-ion battery pack was simulated by ANSYS to determine the temperature gradient of the cooling system and lithium-ion batteries. Simulation outcomes demonstrated that the lithium-ion battery pack's temperature distributions could be remarkably influenced by the flow arrangement and fluid coolant type.
\end{abstract}

Keywords: lithium titanate oxide lithium-ion battery; battery pack thermal management

\section{Introduction}

Lithium-ion batteries were appointed as an alternative for e-mobility utilizations attributable to their excellent performance. Furthermore, there is a continuing demand to advance lithium-ion battery characteristics to lengthen the period in which they can be utilized. The lifetime, power output and energy storage capacity are principal performance characteristics for renewable energy storage utilization.

Different research [1-4] has studied the thermal management of lithium-ion batteries. Several consequences were utilized to parameterize the recommended thermal model of the lithium-ion batteries. Different cooling strategies have been studied for lithiumion batteries with dissimilar coolants including phase change material, mineral oil and air, water and heat pipes. Water-based cooling arrangements have brought about much consideration between the different coolants and cooling procedures because water has good thermal properties as a coolant [5].

Mineral oil, attributable to its dielectric behavior, might be employed for direct liquid cooling with superior efficiency; nevertheless, feasibility for the application requires examination [6]. Air-based cooling arrangements benefit from a simplified configuration and low maintenance cost; nevertheless, they suffer from restrictions in the most significant heat dissipation capacity. Moreover, the noise problem attributable to the immense fan speed makes it unacceptable [7]. Combining phase change materials into the cooling arrangement has presented the benefit of temperature distribution homogeneity; nevertheless, the small cooling efficiency problem needs to be resolved [8].

Different cooling methods were studied. Water-based cooling approaches offer adequate cooling and have the benefit of less volume demand attributable to compactness. A numerical and experimental investigation of prismatic lithium-ion battery cells' thermal behavior was accomplished by employing a mini-channel cold plate. Computational fluid 
dynamics simulations were used in the optimization and configuration of lithium-ion battery cooling systems. It should be noted that important automotive manufacturing companies including General Motors, Hyundai and Tesla are employing water-based cooling procedures for the thermal management of the lithium-ion batteries in electric vehicles [9].

Heat generation coming out of experimental measurements were compared with heat generation specified from the thermal model. The heat generation was calculated using reversible and irreversible heat supplies in a lithium-ion battery cell. The experimental heat generation was quantified employing an isothermal battery calorimeter. The lithium-ion battery's heat loss throughout operating was approximated by accumulating two essential sources: reversible and irreversible heat [10].

Lithium-ion batteries should work at optimum temperatures in an extensive range of environmental temperatures and working conditions to achieve maximum utilization of lithium-ion batteries in electric vehicles $[11,12]$. The aforementioned is essential, especially with fast charging and discharging cycles. Factors affecting the temperature of lithium-ion batteries are illustrated in Figure 1.

Lithium-ion battery thermal management is indispensable in attaining the functioning and lengthening of lithium-ion batteries' life in electric vehicles. One of the critical issues of employing lithium-ion batteries in electric and hybrid vehicles is appropriate thermal management. Proper thermal management is essential with the intention of controlling degradation at a satisfactory rate. It is crucial to decrease the risk of thermal runaway. Figure 2 demonstrates a comparison between direct liquid cooling and air cooling. Figure 3 shows and describes an example of a lithium-ion battery cooling system.

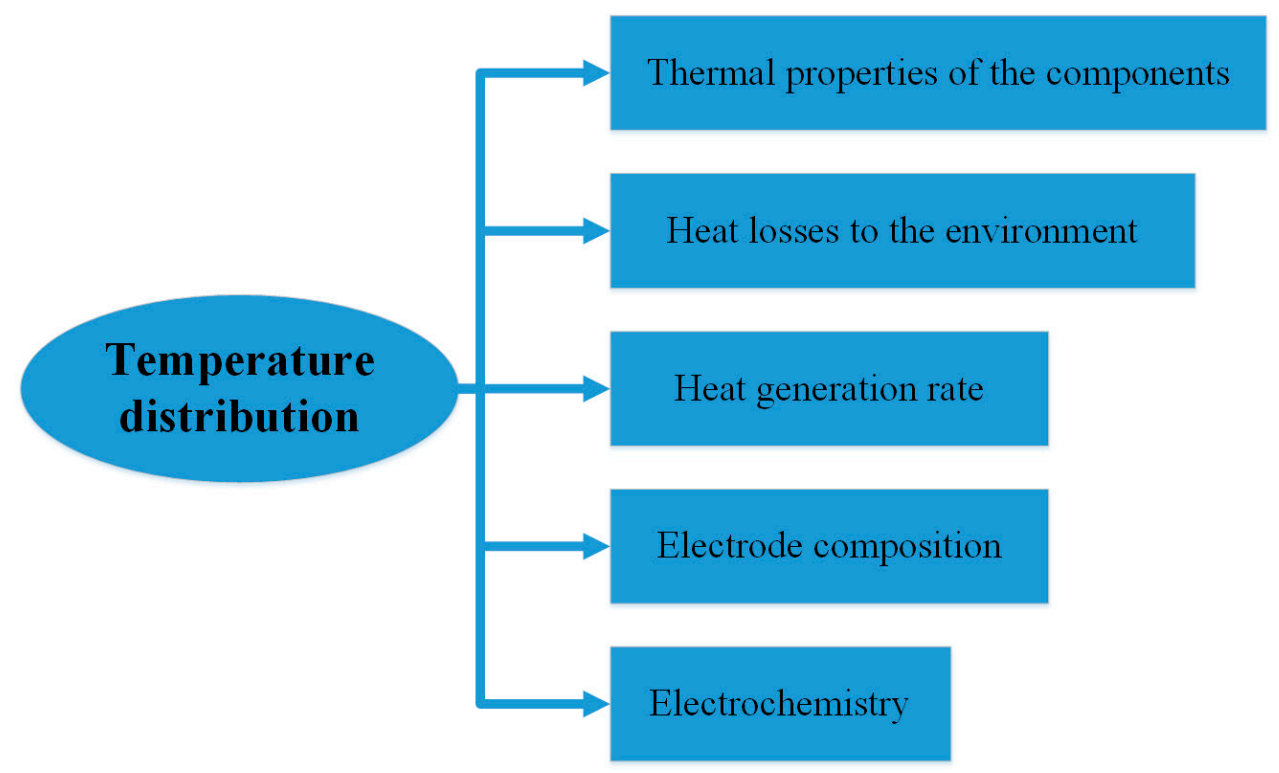

Figure 1. Factors affecting the temperature of the battery [13].

The investigation regarding lithium-ion batteries has increased enormously across the world and different researchers have studied different aspects of the thermal management of lithium-ion batteries. However, the thermal management of lithium titanate oxide-based lithium-ion batteries has been studied less than the other features. The heat generation model of lithium-ion batteries was simplified. Nevertheless, without much research heretofore, a dynamic heat generation model has not been developed using experimental data from isothermal battery calorimeter model number 284 from NETZSCH. Consequently, this research objective is to introduce and help analyze a thermal management system through the precise determination of the heat generation of lithium titanate oxide batteries. 
Thermal management of lithium-ion battery

\section{Air cooling

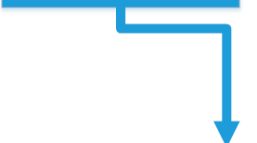

-Air cooling is simple to circulate by employing fans. -Air cooling does not need considerable weight. -Air cooling is the simplest and lightest method. -Air cooling uses the most parasitic energy. -A minimum average temperature increase confines air cooling -The fan energy and heat transfer coefficient range restricts the application of air cooling.

Figure 2. Comparison between direct liquid cooling and air cooling [14].
-Direct liquid cooling appends additional weight to the battery pack -Direct liquid cooling requires a more complicated system for circulation. -Liquid leakage problem should be considered indirect liquid cooling. -Liquid cooling is much more complicated than air-cooling from different aspects, including flow distribution and the pack level.

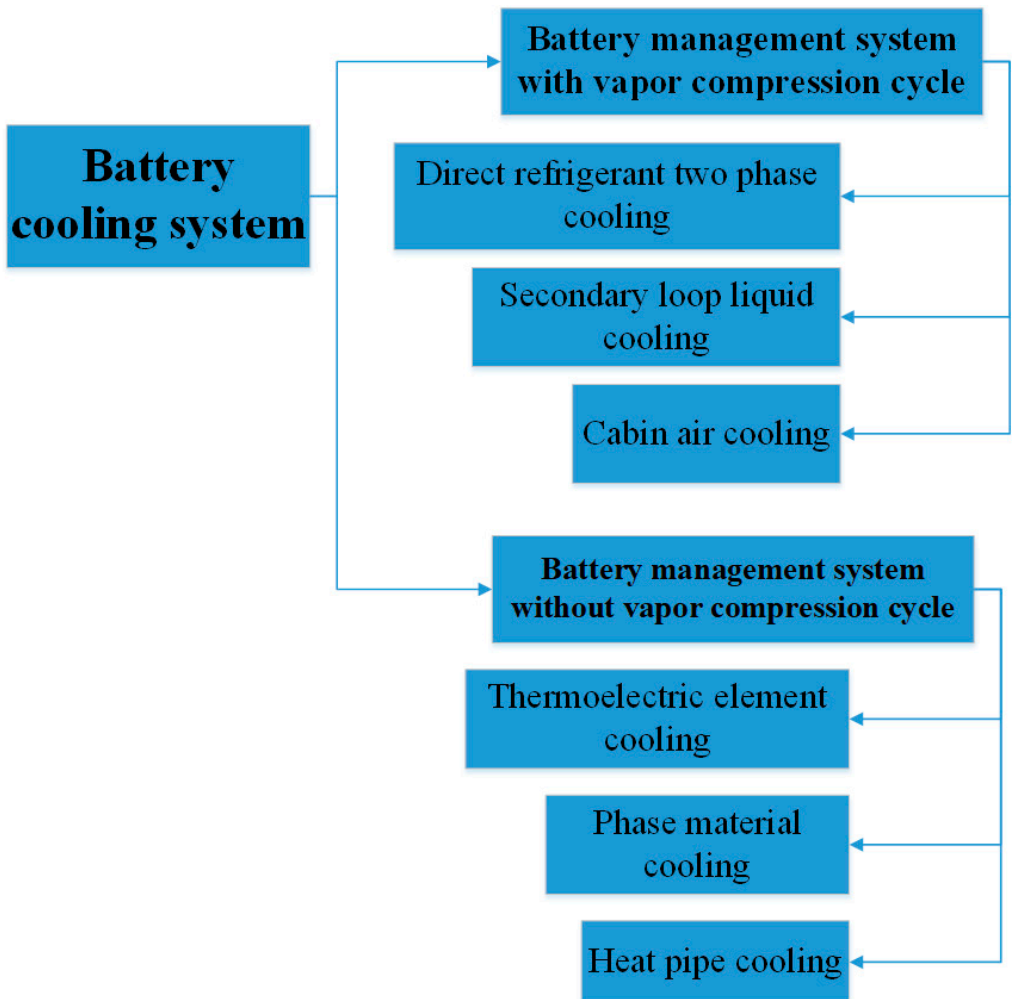

Figure 3. An example of a battery cooling system [15]. 


\section{Methodology}

It is crucial to understand the lithium-ion batteries' heat generation behavior notably during rapid discharging and charging conditions for different applications, specifically in electric vehicles. The aforementioned is necessary to construct a thermal management system for lithium-ion batteries. The present investigation studied the thermal management of a lithium-ion battery pack. The constant voltage and constant current method were employed to fully charge the lithium titanate oxide-based lithium-ion battery until an allowable voltage of $2.7 \mathrm{~V}$ and a cut-off current of 0.52 was achieved. Afterward, the lithium-ion battery was discharged with a constant current including $39 \mathrm{~A}, 52 \mathrm{~A}$ and $65 \mathrm{~A}$ until a cut-off voltage of $1.5 \mathrm{~V}$ was reached. A full discharge cycle was applied to the lithium titanate oxide battery as shown in Figure 4. The corresponding heat generation of the lithium titanate oxide battery for different discharge rates is demonstrated in Figure 5.
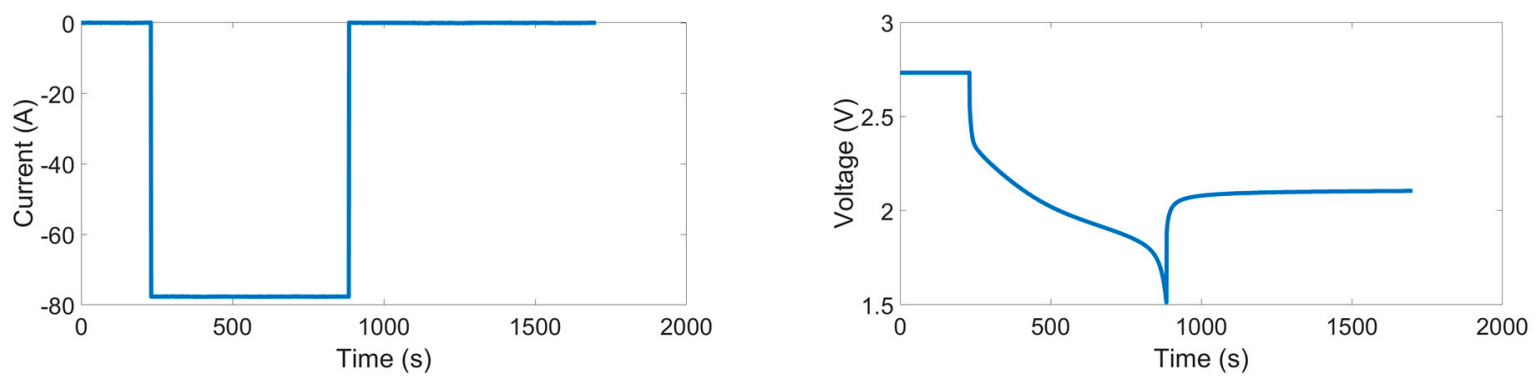

Figure 4. The full discharge cycle procedure.
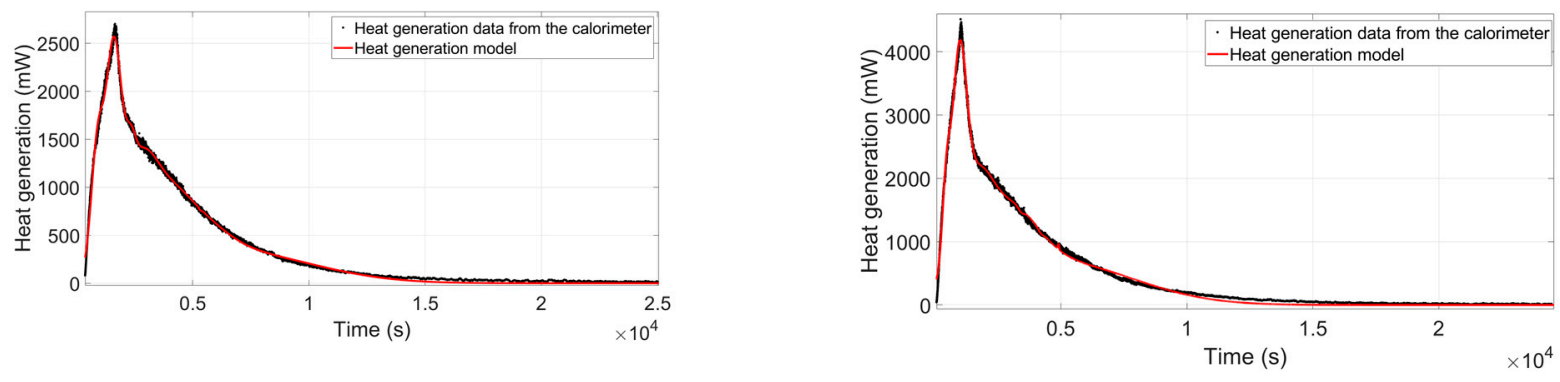

(a)

(b)

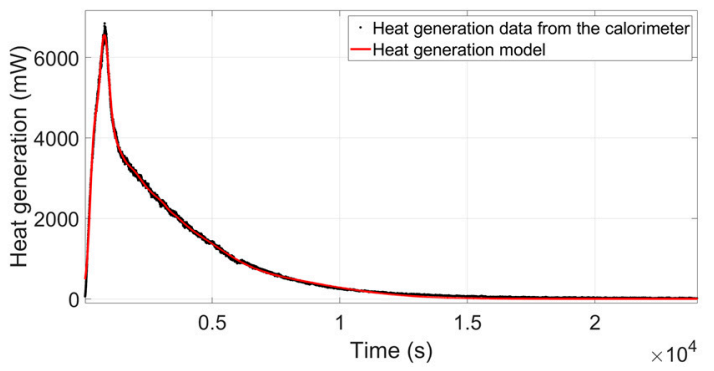

(c)

Figure 5. Heat generation of the lithium titanate oxide battery during: (a) 39 A discharge (b) 52 A discharge (c) 65 A discharge.

All of the experiments were accomplished in the present research by employing an experimental setup (an isothermal battery calorimeter and Maccor system) and recorded with time for all experiments. The experiential prearrangement was controlled by the graphical user interface of the LabVIEW front panel interface.

A total of 13 Ah pouch type commercial lithium titanate oxide lithium-ion battery cells were used in the present research. Lithium titanate oxide-based lithium-ion batteries have a better performance and lengthiest life concerning discharging and charging energy 
capacity and safety over an extensive temperature range compared with other lithiumion batteries [16]. Characteristics of the lithium titanate oxide lithium-ion battery are demonstrated in Figure 6.

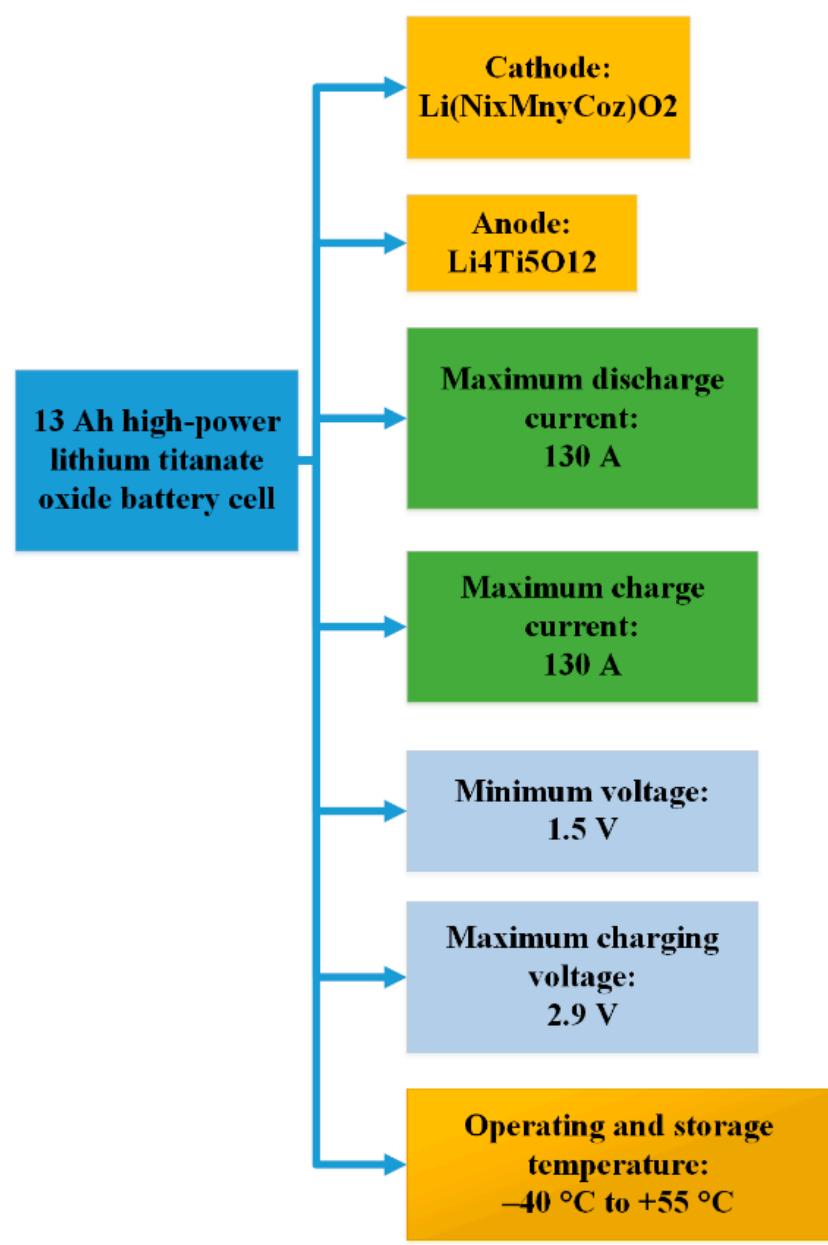

Figure 6. Characteristics of the lithium titanate oxide lithium-ion battery.

In this study, a combination of time-dependent heat generation models and computational fluid dynamics from ANSYS for transient thermal research of the thermal management of lithium-ion battery packs was used. The integration of the heat generation model with ANSYS is illustrated in Figure 7. In the heat generation model, HG $(t)$ is the heat generation $(\mathrm{mW})$ at the time(s) t. Heat generation parameters are demonstrated in Table 1.

The data obtained from isothermal battery calorimeter model number 284 allowed the distinguishing and characterizing of lithium-ion batteries' thermal aspect. It also assisted in developing appropriate arrangements for lithium-ion battery thermal management systems. Suitable modeling can be advantageous to predict the lithium-ion battery's thermal behavior and improve the heat management system's design. Modeling is the cheapest way to investigate the effect of various parameters such as the type of coolant, heat transfer mechanism and system geometry on the thermal management system performance. A representation of the lithium titanate oxide battery pack's research methodology is demonstrated in Figure 8. The parameters of the thermal management system employed in this research are displayed in Table 2. In addition, the properties of air, dielectric water/glycol (50/50) and dielectric mineral oil are shown in the table [17]. 


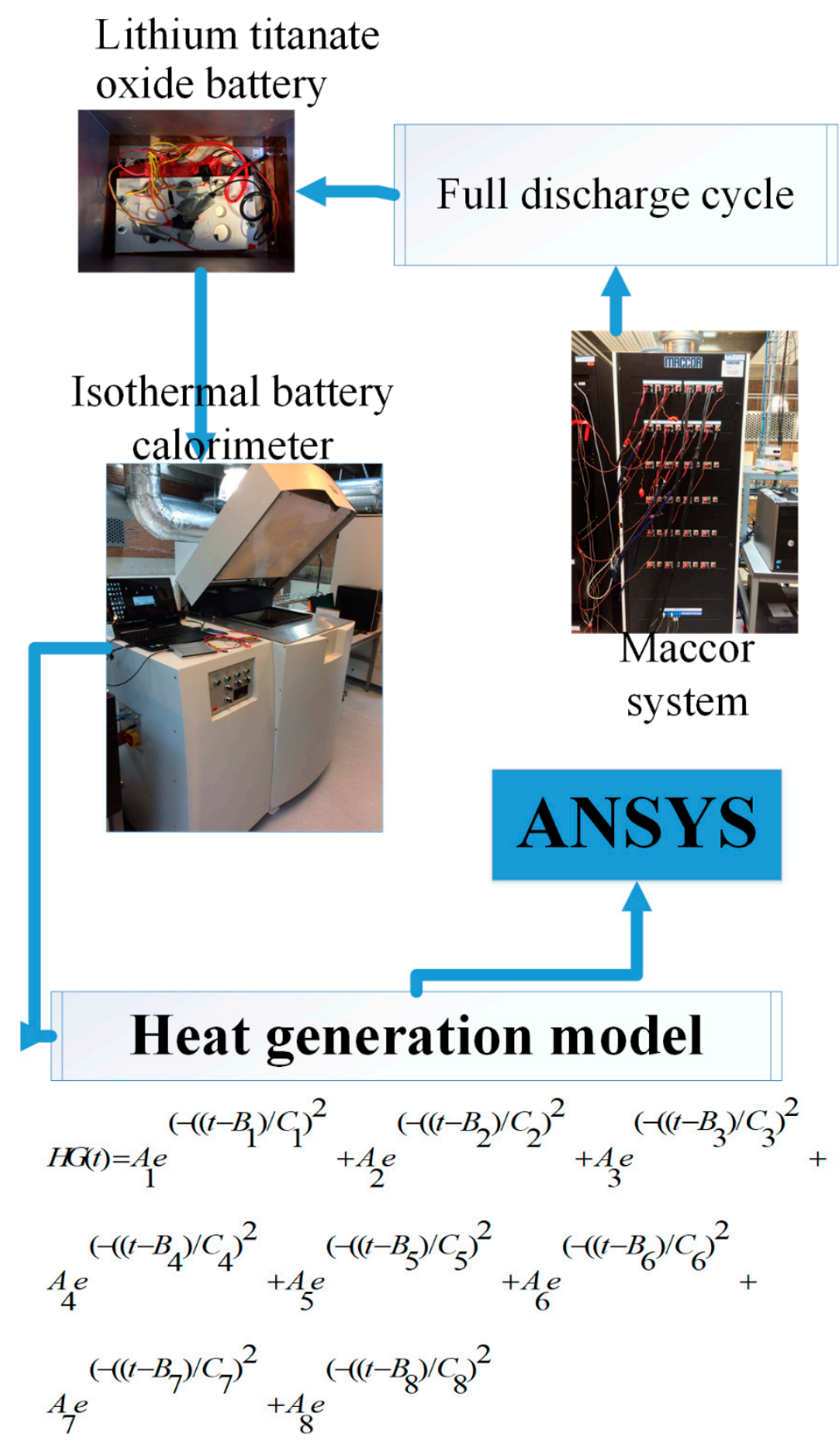

Figure 7. The integration of the heat generation model with ANSYS.

Table 1. Heat generation parameters.

\begin{tabular}{llll}
\hline & $\mathbf{3 9} \mathbf{A}$ & $\mathbf{5 2} \mathbf{A}$ & $\mathbf{6 5} \mathbf{A}$ \\
\hline A1 & 1972 & 2922 & 4519 \\
B1 & 1590 & 967.1 & 724.7 \\
C1 & 468.2 & 398.5 & 286.7 \\
A2 & 1239 & 1116 & 1882 \\
B2 & 900.2 & 1603 & 1066 \\
C2 & 382.9 & 1252 & 443.2 \\
A3 & 316.2 & 454.6 & 1657 \\
B3 & 2334 & 234.3 & 1613 \\
C3 & 286.6 & 1035 & 723.5 \\
A4 & 995.6 & 2818 & 2806 \\
B4 & 2707 & 341.8 \\
\hline
\end{tabular}


Table 1. Cont.

\begin{tabular}{cccc}
\hline & $\mathbf{3 9} \mathbf{A}$ & $\mathbf{5 2} \mathbf{A}$ & $\mathbf{6 5} \mathbf{A}$ \\
\hline C4 & 1147 & 1640 & 211.6 \\
A5 & 142.2 & -61.15 & 1218 \\
B5 & 4275 & 3434 & 2509 \\
C5 & 912.3 & 154.4 & 1152 \\
A6 & -18.58 & -38.59 & -44.68 \\
B6 & 5325 & 4207 & 3343 \\
C6 & 60.5 & 142.3 & 229.3 \\
A7 & 327.1 & 674.7 & 1060 \\
B7 & 6688 & 4821 & 3762 \\
C7 & 4856 & 4333 & 2117 \\
A8 & 493.8 & 91.83 & 616.7 \\
B8 & 4579 & 4907 & 5739 \\
C8 & 1999 & 30.81 & 4784 \\
\hline
\end{tabular}

Table 2. Parameters of the thermal management system.

\begin{tabular}{|c|c|c|}
\hline $\begin{array}{l}\text { Geometrical } \\
\text { Parameters }\end{array}$ & $\begin{array}{l}\text { The total thickness of the lithium titanate oxide battery cell } \\
\text { The vertical distance between the lithium titanate oxide batteries } \\
\text { The horizontal distance between the lithium titanate oxide batteries } \\
\text { and boundaries }\end{array}$ & $\begin{array}{l}9 \mathrm{~mm} \\
4.5 \mathrm{~mm} \\
12 \mathrm{~mm}\end{array}$ \\
\hline \multirow{4}{*}{ Battery Physical Parameters } & $\begin{array}{l}\text { Along-plane thermal conductivity of the lithium titanate } \\
\text { oxide battery }\end{array}$ & $38 \mathrm{~W} / \mathrm{m} \cdot \mathrm{k}$ \\
\hline & Specific heat capacity of the lithium titanate oxide battery & $1196.8 \mathrm{~J} / \mathrm{kg} \cdot \mathrm{k}$ \\
\hline & $\begin{array}{l}\text { Through-plane thermal conductivity of the lithium titanate } \\
\text { oxide battery }\end{array}$ & $0.71 \mathrm{~W} / \mathrm{m} \cdot \mathrm{k}$ \\
\hline & Density of the lithium titanate oxide battery & $1974.01 \mathrm{~kg} / \mathrm{m}^{3}$ \\
\hline \multirow{4}{*}{ Pack Parameters } & The nominal voltage of the lithium titanate oxide battery & $2.26 \mathrm{~V}$ \\
\hline & Number of lithium titanate oxide batteries in the pack & 20 \\
\hline & Lithium titanate oxide battery cell surface area & $26,316 \mathrm{~mm}^{2}$ \\
\hline & The capacity of each lithium titanate oxide battery & $13 \mathrm{Ah}$ \\
\hline \multirow{13}{*}{ Physical Parameters of the Coolant } & Heat transfer coefficient for the cooling media & $25-250 \mathrm{~W} / \mathrm{m}^{2} \mathrm{k}$ \\
\hline & Density of the air & $1.225 \mathrm{~kg} / \mathrm{m}^{3}$ \\
\hline & Specific heat capacity of the air & $1006 \mathrm{~J} / \mathrm{kg} / \mathrm{k}$ \\
\hline & Thermal conductivity of the air & $0.0242 \mathrm{~W} / \mathrm{m} / \mathrm{k}$ \\
\hline & Kinematic viscosity of the air & $1.46 \times 10^{-5} \mathrm{~m}^{2} / \mathrm{s}$ \\
\hline & The density of the dielectric mineral oil & $924.1 \mathrm{~kg} / \mathrm{m}^{3}$ \\
\hline & Specific heat capacity of the dielectric mineral oil & $1900 \mathrm{~J} / \mathrm{kg} / \mathrm{k}$ \\
\hline & Thermal conductivity of the dielectric mineral oil & $0.13 \mathrm{~W} / \mathrm{m} / \mathrm{k}$ \\
\hline & Kinematic viscosity of the dielectric mineral oil & $5.6 \times 10^{-5} \mathrm{~m}^{2} / \mathrm{s}$ \\
\hline & Density of the dielectric water/glycol (50/50) & $1069 \mathrm{~kg} / \mathrm{m}^{3}$ \\
\hline & Specific heat capacity of the dielectric water/glycol $(50 / 50)$ & $3323 \mathrm{~J} / \mathrm{kg} / \mathrm{k}$ \\
\hline & Thermal conductivity of the dielectric water/glycol $(50 / 50)$ & $0.3892 \mathrm{~W} / \mathrm{m} / \mathrm{k}$ \\
\hline & Kinematic viscosity of the dielectric water/glycol $(50 / 50)$ & $2.58 \times 10^{-6} \mathrm{~m}^{2} / \mathrm{s}$ \\
\hline \multirow{5}{*}{ Environmental Parameters } & Ambient temperature ${ }^{\circ} \mathrm{C}$ & $30^{\circ} \mathrm{C}, 20^{\circ} \mathrm{C}$ \\
\hline & The inlet temperature of the cooling media & $30{ }^{\circ} \mathrm{C}, 20^{\circ} \mathrm{C}$ \\
\hline & Inlet air velocity & $20 \mathrm{~m} / \mathrm{s}$ \\
\hline & Inlet Water/glycol (50/50) velocity & $0.08 \mathrm{~m} / \mathrm{s}$ \\
\hline & Inlet dielectric mineral oil velocity & $0.08 \mathrm{~m} / \mathrm{s}$ \\
\hline
\end{tabular}




\section{Assumptions:}

-The effect of temperature on the chemical and physical properties of materials was not considered.

-The heat conductivity coefficients in the identical direction of the lithium-ion battery is identical.

-The heat loss of thermal radiation inside the lithium-ion battery was ignored.

-The grid independence study was accomplished to verify the correctness of the simulation model

-A k- $\varepsilon$ two-equation turbulent model accompanied by a standard wall function and a Green-Gauss

technique were used for the simulations.

-The gravity effect being considered.

-A second-order upwind strategy was adopted

-Turbulence model was used in ANSYS Fluent for direct liquid cooling.

-The flow was considered turbulent, steady state and incompressible for liquid cooling

-A uniform free stream velocity inlet boundary condition for incompressible flow was applied.

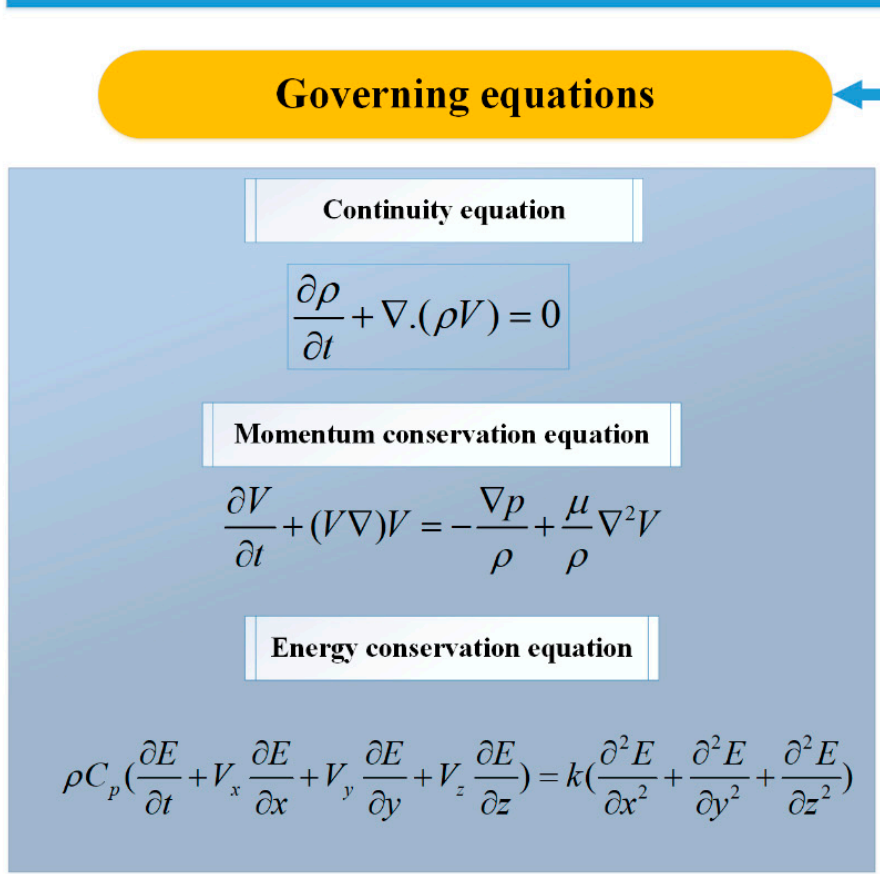

ANSYS

Preprocessing:

-Create and analyze battery geometry and mesh

-Introduce boundary conditions

-Introduce parameter values

-Operational settings

Solution of the model

- Set boundary, subdomain, solver control and conditions

-Solve the thermal problem accompanied by cooling

-Define heat source inside the battery

-Convergence or maximum number of iterations
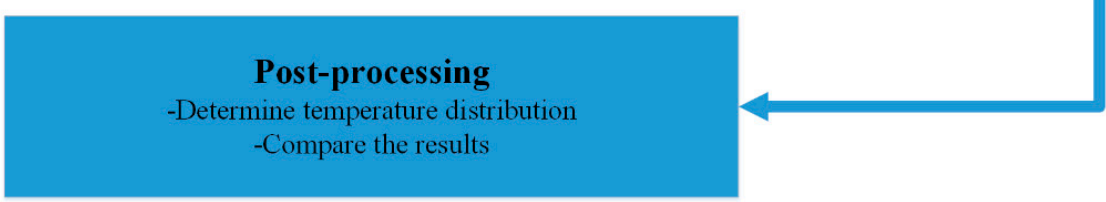

Figure 8. The representation of the research methodology of the battery pack. 


\section{Result and Discussion}

An electric vehicle lithium-ion battery pack was contained within lithium-ion battery cells stacked side by side without chilling facades excluding the pack exterior surface. The inner lithium-ion battery cells in the pack were more prone to overheating. A thermal management system is crucial because lithium-ion batteries should work at an optimal working temperature range. Without an appropriate thermal management system, there is a risk of thermal runaway.

The battery pack thermal simulation employing numerical approaches was significantly advantageous. The aforementioned assisted in comprehending how diverse configuration parameters changed the battery pack's thermal behavior. In the present research, the thermal analysis of commercial-sized lithium-ion batteries under various functioning circumstances was studied experimentally and mathematically. The present research's principal purpose was to evaluate if and how the lithium-ion battery thermal management system could be used to assure lithium-ion battery pack safety and increase lithium-ion batteries' lifetime.

The present research investigated different configurations for the cooling system of a lithium-ion battery pack. The heat dissipation of the lithium-ion battery was achieved from an isothermal battery calorimeter. Different configurations with dissimilar lithium titanate oxide battery arrangements were studied. Various quantities of outlets and inlets and locations of the air cooling system's entrance and exit were compared. A few of the different cooling configurations are illustrated in Table 3.

Table 3. Different cooling configurations.

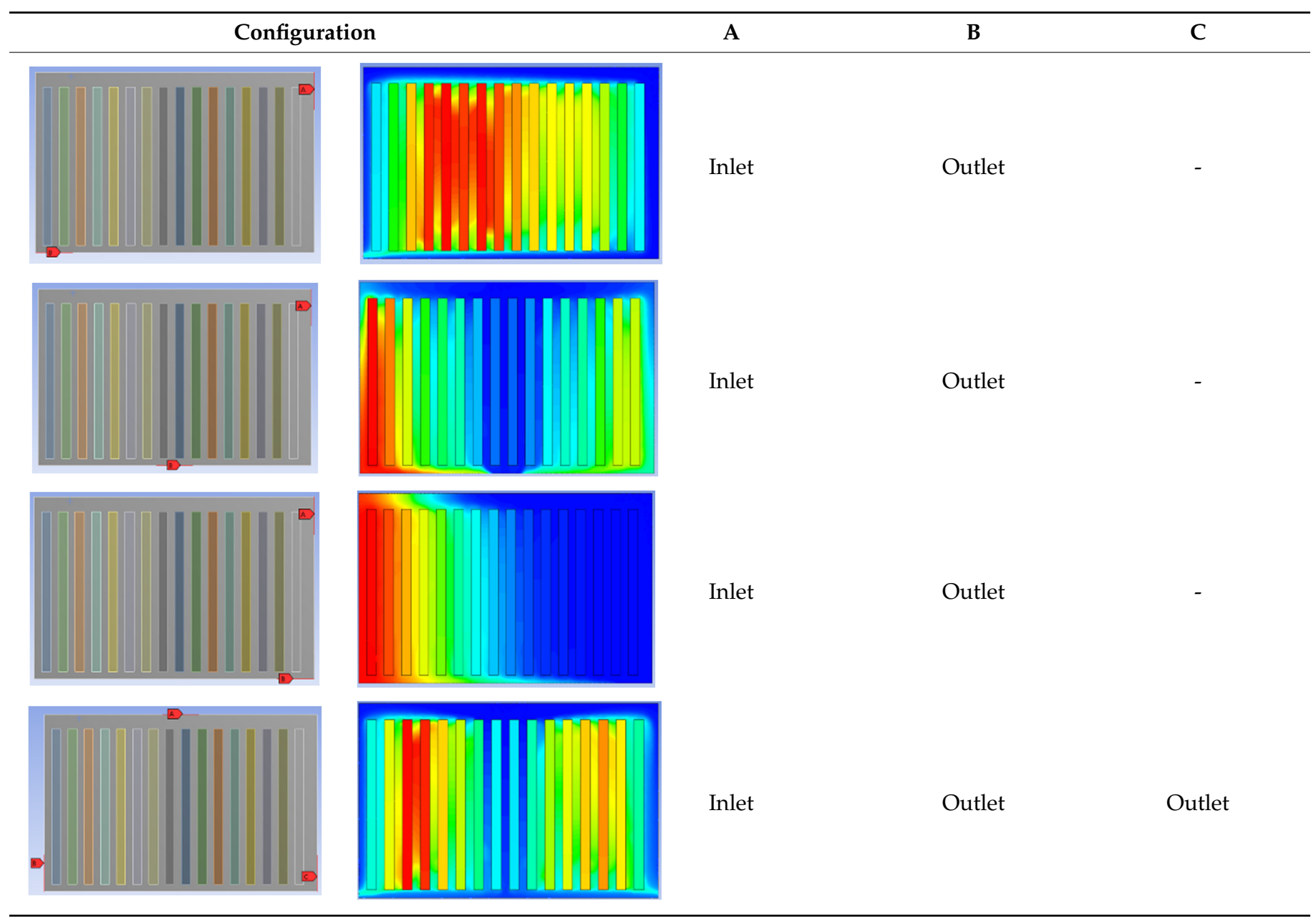


Three different cooling fluids including air, dielectric water/glycol (50/50) and dielectric mineral oil were used and different flow arrangements were proposed. The fluid inlet velocity was considered $20 \mathrm{~m} / \mathrm{s}, 0.08 \mathrm{~m} / \mathrm{s} 0.08 \mathrm{~m} / \mathrm{s}$ for air, dielectric mineral oil and dielectric water/glycol (50/50), correspondingly. The lithium-ion battery assembly's modeling results including the temperature distribution inside the assembly for different coolant arrangements during a 52 A discharge are shown in Figure 9. The thermal management of the lithium-ion battery pack by using air is shown in Figure 9a. The thermal management of the lithium-ion battery pack by using dielectric mineral oil is shown in Figure 9 b. Figure $9 \mathrm{c}$ demonstrates dielectric water/glycol (50/50) cooling.

The black arrows inside each figure show the direction of movement of the cooling fluid flow inside the lithium-ion battery set. As can be seen, the fluid entered the collection from a corner and exited the collection from another corner on the same or a different side. As also seen in some parts, the lithium-ion batteries' heat was not well managed. In other words, the cooling system was not able to remove the produced heat proportionally. The aforementioned may be due to the low flow and high temperature of the coolant around them. This caused a high temperature difference between the lithium-ion batteries.

In comparison with the airflow arrangement, the maximum temperature was reduced for other cooling liquids. However, a more uniform temperature distribution was not obtained. A few of the lithium-ion batteries in the arrangement experienced higher temperatures than other batteries. The aforementioned could be due to receiving less flow of coolant compared with other lithium-ion batteries.

As can be seen in Figure 9, the lithium-ion batteries near the inlet duct had dissipated their generated heat well. The aforementioned could be due to their proximity to the inlet duct and higher flow rate and lower adjacent fluid temperature. Notwithstanding the side, the lithium-ion batteries did not dissipate heat well even with a fluid such as dielectric mineral oil and dielectric water/glycol (50/50). The cooling fluid around these lithium-ion batteries had a lower flow rate and it had a higher temperature due to heat exchange with other lithium-ion batteries.

Dielectric water/glycol (50/50), due to a higher density, produced a higher pressure drop. High values of pressure drop and temperature variation can be justified by high kinematic viscosity and low thermal conductivity of dielectric mineral oil. As shown in Figure 9, due to the bigger specific heat capacity and thermal conductivity of dielectric water/glycol (50/50), the maximum temperature decreased more compared with air and dielectric mineral oil. In all flow arrangements and for all fluids, lithium-ion batteries' temperature was nearer the fluid outlet. The aforementioned may be due to the increase in coolant temperature in these areas. This led to a non-uniform temperature distribution inside the assembly.

Air produces less pressure drop because of its lower viscosity even for higher flow rates. Therefore, the fan cost decreases compared with the pumping costs of dielectric water/glycol (50/50) and dielectric mineral oil. Nevertheless, due to air's low heat capacity, the results were not satisfied even with high flow rates. The maximum temperature for all flow configurations was much higher than other cooling fluids. In general, it seemed that the use of dielectric water/glycol (50/50) and dielectric mineral oil could be a better choice for heat management of the lithium-ion battery assembly at high discharge rates.

Dielectric mineral oil offers more acceptable results compared with air cooling in terms of maximum temperature due to its higher heat capacity than air even at much lower flow rates. Although the costs associated with pressure drop and power consumption are much higher than air, the temperature uniformity is still unacceptable. There was still the problem of increasing the fluid temperature in some areas even when using dielectric water/glycol (50/50) as a coolant. This could be due to the decrease of flow fluid around the lithium-ion batteries compared with other arrangements. 

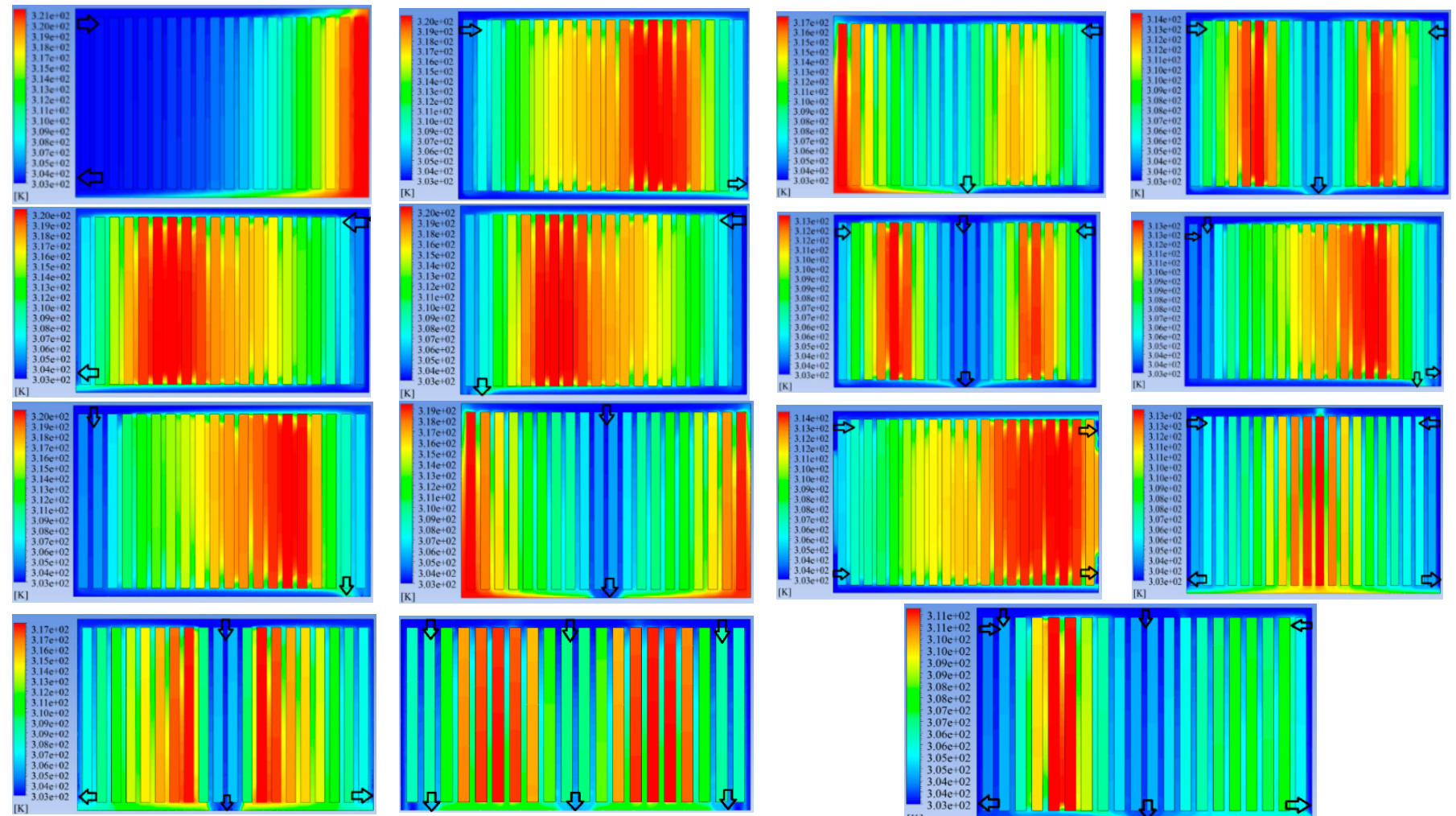

(a)

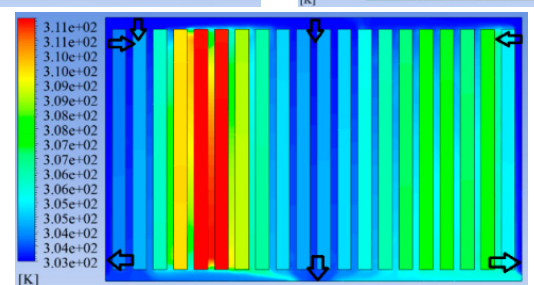

(b)
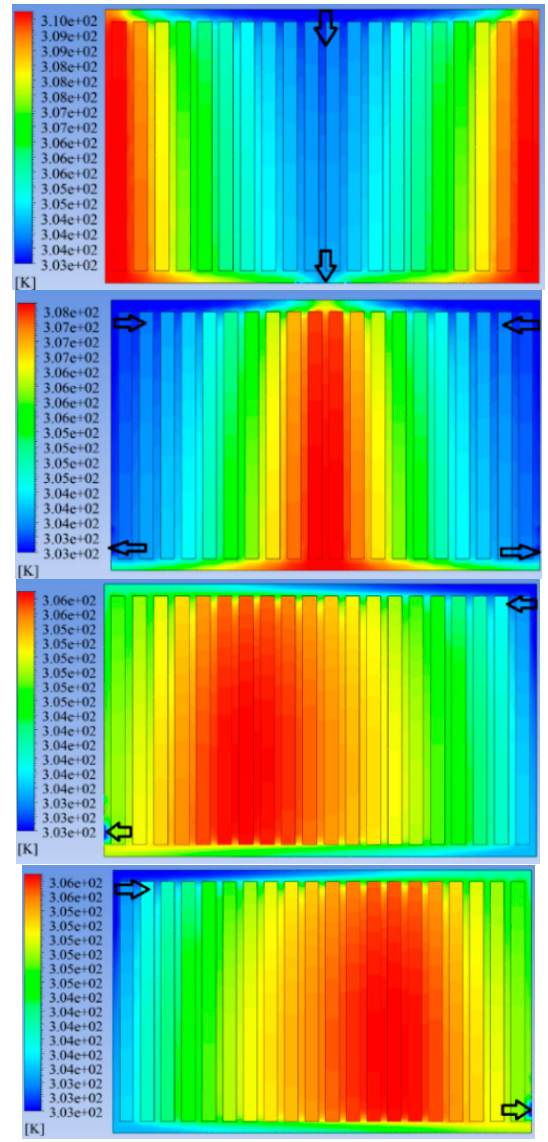

(c)

Figure 9. Thermal management of the lithium-ion battery pack by using (a) air cooling, (b) dielectric mineral oil cooling and (c) dielectric water/glycol (50/50) cooling. 
Figure 10 illustrates the lithium-ion battery pack's air cooling while the air velocity was $20 \mathrm{~m} / \mathrm{s}$ during different full discharge cycles. The initial pack temperature, ambient temperature and the inlet temperature of the cooling media were assumed to be $20^{\circ} \mathrm{C}$. Three different values, including $39 \mathrm{~A}, 52 \mathrm{~A}$ and $65 \mathrm{~A}$, were considered for the discharge rate. As can be seen in the Figures, the distance between the lithium titanate oxide batteries was increased to investigate the effect of battery distance on the system's cooling capability. Although the temperature distribution was more homogenous compared with other cases, the maximum temperature decreased. Hot spot regions demonstrated a crucial mechanism in the battery thermal management sketch.
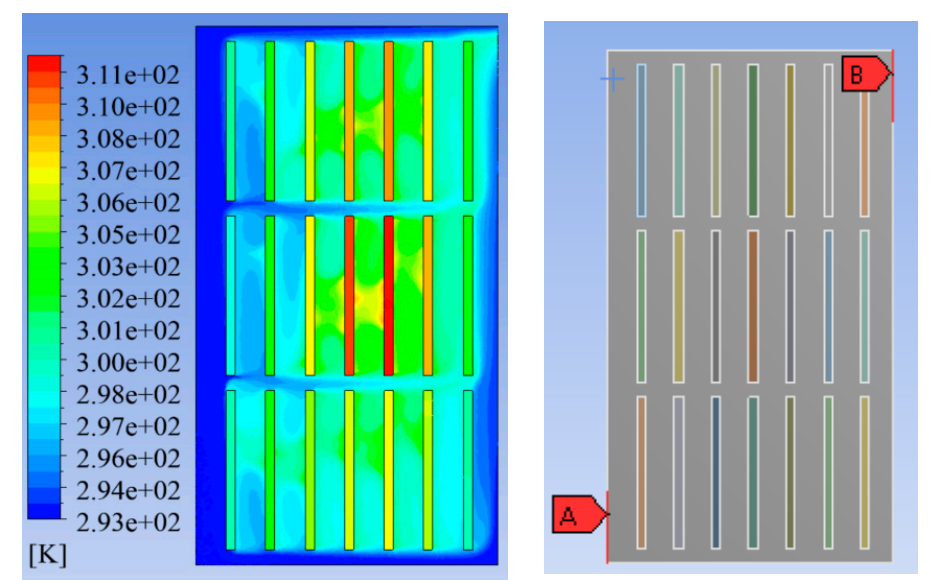

(a)
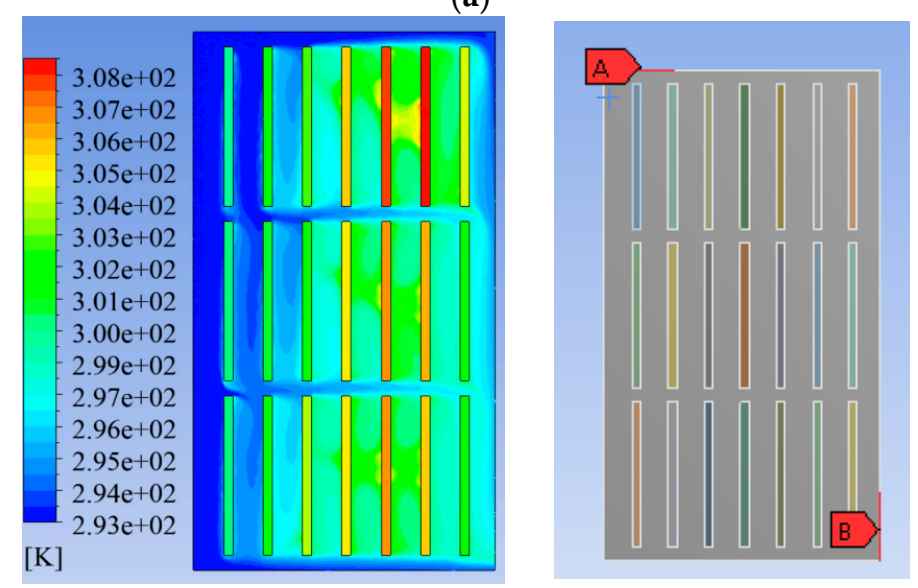

(b)
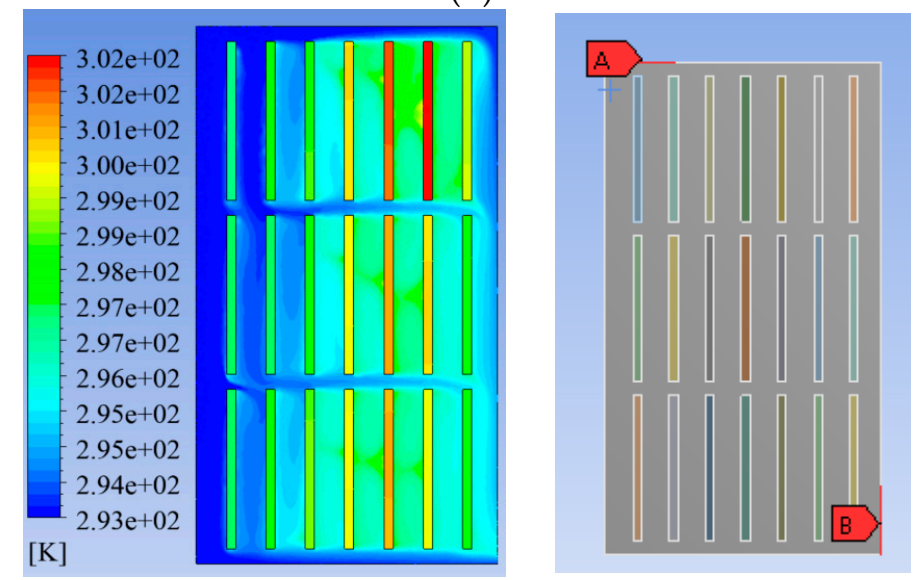

(c)

Figure 10. Air cooling of the lithium-ion battery pack V = 20: (a) 65 A discharge, (b) 52 A discharge, (c) 39 A discharge. 
It should be noted that by increasing the current rate, a greater volume of cooling air was needed. The extra cooling capacity may be insignificant to provide a temperature homogeneity with coolant velocity enhancement. As shown in Figure 10, it could be concluded that air cooling could not provide a homogenous temperature distribution even at high velocities.

\section{Conclusions}

A battery pack simulation was accomplished through ANSYS to study temperature evolution within the battery pack during the time that the cooling fluid was flowing. The temperature distribution in the battery pack has been illustrated. This study's objective was to design and analyze an appropriate thermal management system for a lithium titanate oxide lithium-ion battery pack through the lithium titanate oxide batteries' heat dissipation measurements and thermal performance. The instrument used in this investigation was an isothermal battery calorimeter. The lithium-ion battery cells employed in this investigation were 13 Ah high-power lithium titanate oxide lithium-ion battery cells. A comparison between different cooling methods was accomplished. Dielectric water/glycol (50/50), dielectric mineral oil and air were considered cooling fluids in different flow configurations. It was shown that the combination of computational fluid dynamics and dynamic heat generation models could be an intuitionistic approach for the transient thermal research of lithium-ion battery packs. Although air does not require much power to move inside an arrangement, high flow rates will not be able to cool the lithium titanate oxide lithium-ion batteries and control their temperature during rapid discharging and a high working temperature. Due to its high viscosity and pressure drop, dielectric mineral oil does not seem appropriate although decreasing lithium titanate oxide batteries' maximum temperature works better than air. The fluid that produced more acceptable results between the investigated cooling fluids especially for high discharge rates in terms of maximum temperature and temperature deviations was dielectric water/glycol $(50 / 50)$ because of its high heat capacity, suitable viscosity and distribution capability. It was shown how the flow arrangements could influence the temperature profile of the cooling system and lithium titanate oxide batteries. The results showed that flow arrangements with more than one input or output could decrease the maximum temperature more than a single inlet and outlet. The results of this work can be used for the optimization of a lithium titanate oxide battery thermal management system. As proper and optimal temperature control in lithium-ion batteries is very important, studying their control behavior from other aspects and using various criteria can be very important and influential in different design and construction stages and choosing between various designs. More work needs to be done in additional areas including a multi-objective optimization of the system. The optimization objective could be to minimize the maximum battery temperature and pressure drop of the system. Consequently, the best flow rate can be determined for each current rate.

Author Contributions: S.S.M. proposed the idea of the paper; S.S.M. wrote the paper; E.S. provided suggestions on the content and structure of the paper; S.K.K. and E.S. has been reviewing the draft manuscripts. All authors have read and agreed to the published version of the manuscript.

Funding: This research received no external funding.

Institutional Review Board Statement: Not applicable.

Informed Consent Statement: Not applicable.

Data Availability Statement: The data presented in this study are available from the corresponding author upon request.

Conflicts of Interest: The authors declare no conflict of interest.

\section{References}

1. Bao, Y.; Fan, Y.; Chu, Y.; Ling, C.; Tan, X.; Yang, S. Experimental and Numerical Study on Thermal and Energy Management of a Fast-Charging Lithium-Ion Battery Pack with Air Cooling. J. Energy Eng. 2019, 145, 04019030. [CrossRef] 
2. Erb, D.C.; Kumar, S.; Carlson, E.; Ehrenberg, I.M.; Sarma, S.E. Analytical methods for determining the effects of lithium-ion cell size in aligned air-cooled battery packs. J. Energy Storage 2017, 10, 39-47. [CrossRef]

3. Cheng, L.; Garg, A.; Jishnu, A.K.; Gao, L. Surrogate based multi-objective design optimization of lithium-ion battery air-cooled system in electric vehicles. J. Energy Storage 2020, 31, 101645. [CrossRef]

4. Yang, W.; Zhou, F.; Zhou, H.; Liu, Y. Thermal performance of axial air cooling system with bionic surface structure for cylindrical lithium-ion battery module. Int. J. Heat Mass Transf. 2020, 161, 120307. [CrossRef]

5. Deng, Y.; Feng, C.; Zhu, J.E.H.; Chen, J.; Wen, M.; Yin, H. Effects of different coolants and cooling strategies on the cooling performance of the power lithium ion battery system: A review. Appl. Therm. Eng. 2018, 142, 10-29. [CrossRef]

6. Seo, J.H.; Patil, M.S.; Kim, D.W.; Bang, Y.M.; Lee, M.Y. Numerical Study on the Cooling Performances of Various Cooling Methods for Laminated Type Battery. In Proceedings of the 1st ACTS-Asian Conference on Thermal Sciences, Jeju Island, Korea, 26-30 March 2017.

7. Saw, L.H.; Ye, Y.; Tay, A.A.O.; Chong, W.T.; Kuan, S.H.; Yew, M.C. Computational fluid dynamic and thermal analysis of Lithium-ion battery pack with air cooling. Appl. Energy 2016, 177, 783-792. [CrossRef]

8. Ling, Z.; Cao, J.; Zhang, W.; Zhang, Z.; Fang, X.; Gao, X. Compact liquid cooling strategy with phase change materials for Li-ion batteries optimized using response surface methodology. Appl. Energy 2018, 228, 777-788. [CrossRef]

9. Panchal, S.; Khasow, R.; Dincer, I.; Agelin-Chaab, M.; Fraser, R.; Fowler, M. Thermal design and simulation of mini-channel cold plate for water cooled large sized prismatic lith-ium-ion battery. Appl. Therm. Eng. 2017, 122, 80-90. [CrossRef]

10. Madani, S.S.; Schaltz, E.; Kær, S.K. Thermal Modelling of a Lithium Titanate Oxide Battery. ECS Trans. 2018, 87, 315-326. [CrossRef]

11. Ye, Y.; Saw, L.H.; Shi, Y.; Tay, A.A.O. Numerical analyses on optimizing a heat pipe thermal management system for lithium-ion batteries during fast charging. Appl. Therm. Eng. 2015, 86, 281-291. [CrossRef]

12. Pesaran, A.; Santhanagopalan, S.; Kim, G. Addressing the Impact of Temperature Extremes on Large Format Li-Ion Batteries for Vehicle Applications (Presentation); Technical Report; National Renewable Energy Laboratory (NREL): Golden, CO, USA, 2013.

13. Han, X.; Lu, L.; Zheng, Y.; Feng, X.; Li, Z.; Li, J.; Ouyang, M. A review on the key issues of the lithium ion battery degradation among the whole life cycle. eTransportation 2019, 1, 100005. [CrossRef]

14. Chen, D.; Jiang, J.; Kim, G.H.; Yang, C.; Pesaran, A. Comparison of different cooling methods for lithium ion battery cells. Appl. Therm. Eng. 2016, 94, 846-854. [CrossRef]

15. Kim, J.; Oh, J.; Lee, H. Review on battery thermal management system for electric vehicles. Appl. Therm. Eng. 2019, 149, 192-212. [CrossRef]

16. Stroe, A.-I. Analysis of Performance and Degradation for Lithium Titanate Oxide Batteries Stroe. Ph.D. Thesis, Aalborg Universitet, Esbjerg, Denmark, 2018.

17. Kim, G.-H.; Pesaran, A.A. Battery thermal management system design modeling. In Proceedings of the 22nd International Battery, Hybrid and Fuel Cell Electric Vehicle Conference and Exhibition (EVS-22), Yokohama, Japan, 23-28 October 2006. 